Keywords: melanoma; ASM inhibitors; SMPD1; functional acid sphingomyelinase inhibitors; cholesterol transport inhibitors; lysosomotropism; autophagy

\title{
Modulating cancer cell survival by targeting intracellular cholesterol transport
}

\author{
Omer F Kuzu ${ }^{1}$, Raghavendra Gowda ${ }^{1,2,3}$, Mohammad A Noory ${ }^{1}$ and Gavin P Robertson ${ }^{\star}, 1,2,3,4,5,6$ \\ ${ }^{1}$ Department of Pharmacology, The Pennsylvania State University College of Medicine, Hershey, PA 17033, USA; ${ }^{2}$ Penn State \\ Hershey Melanoma Center, The Pennsylvania State University College of Medicine, Hershey, PA 17033, USA; ${ }^{3}$ Penn State \\ Melanoma Therapeutics Program, The Pennsylvania State University College of Medicine, Hershey, PA 17033, USA; ${ }^{4}$ Department \\ of Pathology, The Pennsylvania State University College of Medicine, Hershey, PA 17033, USA; ${ }^{5}$ Department of Dermatology, The \\ Pennsylvania State University College of Medicine, Hershey, PA 17033, USA and ${ }^{6}$ Department of Surgery, The Pennsylvania State \\ University College of Medicine, Hershey, PA 17033, USA
}

Background: Demand for cholesterol is high in certain cancers making them potentially sensitive to therapeutic strategies targeting cellular cholesterol homoeostasis. A potential approach involves disruption of intracellular cholesterol transport, which occurs in Niemann-Pick disease as a result of acid sphingomyelinase (ASM) deficiency. Hence, a class of lysosomotropic compounds that were identified as functional ASM inhibitors (FIASMAs) might exhibit chemotherapeutic activity by disrupting cancer cell cholesterol homoeostasis.

Methods: Here, the chemotherapeutic utility of ASM inhibition was investigated. The effect of FIASMAs on intracellular cholesterol levels, cholesterol homoeostasis, cellular endocytosis and signalling cascades were investigated. The in vivo efficacy of ASM inhibition was demonstrated using melanoma xenografts and a nanoparticle formulation was developed to overcome doselimiting CNS-associated side effects of certain FIASMAs.

Results: Functional ASM inhibitors inhibited intracellular cholesterol transport leading to disruption of autophagic flux, cellular endocytosis and receptor tyrosine kinase signalling. Consequently, major oncogenic signalling cascades on which cancer cells were reliant for survival were inhibited. Two tested ASM inhibitors, perphenazine and fluphenazine that are also clinically used as antipsychotics, were effective in inhibiting xenografted tumour growth. Nanoliposomal encapsulation of the perphenazine enhanced its chemotherapeutic efficacy while decreasing CNS-associated side effects.

Conclusions: This study suggests that disruption of intracellular cholesterol transport by targeting ASM could be utilised as a potential chemotherapeutic approach for treating cancer.

Cholesterol has an important role in the development of certain malignancies (Montero et al, 2008; Freed-Pastor et al, 2012; Smith and Land, 2012; Sorrentino et al, 2014). Epidemiological studies have shown that elevated serum cholesterol levels can be associated with cancer risk (Platz et al, 2008; Nielsen et al, 2013). Preclinical studies also demonstrate that deregulated intracellular cholesterol homoeostasis can promote cancer development (Montero et al, 2008; Smith and Land, 2012). More recently, an increase in cellular cholesterol demand was reported with EGFR or RAS-mediated oncogenic transformation (Gabitova et al, 2015). Hindering intracellular cholesterol levels by reducing the expression of lowdensity lipoprotein (LDL) receptors or enhancing expression of cholesterol exporters, impeded the growth of skin tumours (Gabitova et al, 2015). Activation of AKT signalling following loss of tumour suppressor PTEN, a genetic alteration observed in many cancers, triggered cholesteryl ester accumulation in prostate cancer

*Correspondence: Dr GP Robertson; E-mail: gprobertson@psu.edu

Received 2 May 2017; revised 11 May 2017; accepted 5 June 2017; published online 11 July 2017

(C) 2017 Cancer Research UK. All rights reserved 0007-0920/17 
cells (Yue et al, 2014). Importantly, blocking the cholesterol accumulation-reduced cancer cell proliferation and suppressed xenografted tumour growth (Yue et al, 2014). Moreover, in breast cancers, loss of tumour suppressor p53-induced cancer cell proliferation and self-renewal by upregulating of the cholesterol synthesis pathway (Sorrentino et al, 2014). Collectively these studies suggest that therapeutically modulating cholesterol homoeostasis could be useful for inhibiting cancer development.

Targeting intracellular cholesterol transport with leelamine, a naturally derived lysosomotropic compound, has recently been shown to retard melanoma tumour growth (Kuzu et al, 2014). Leelamine-mediated cancer cell death is associated with the shutdown of cholesterol egress from lysosomal/late endosomal cell compartments. Inhibition of lysosomal cholesterol efflux also occurs in a lipid storage disorder called Niemann-Pick disease (Vanier, 2013), loss of function mutations in sphingomyelin phosphodiesterase-1 (SMPD1), which encodes acid sphingomyelinase (ASM), causes types A and B forms of the Niemann-Pick disease (Vanier, 2013). This lysosomal enzyme breaks down sphingomyelin to phosphorylcholine and ceramide. Lack of functional ASM, impairs sphingosine efflux from lysosomes, blocks late endosome-lysosome fusion and causes accumulation of sphingolipid, as well as LDL-derived cholesterol in lysosomes (Lloyd-Evans et al, 2008). However, it is currently unknown whether ASM inhibitors could be used to block intracellular cholesterol transport to treat cancer.

A class of lysosomotropic antidepressant, antipsychotic or antihistamine drugs have been identified as functional ASM inhibitors (FIASMAs) (Kornhuber et al, 2008; Kornhuber et al, 2011). These compounds have also been reported to be effective against cancer in preclinical and large-scale case-control studies (Akiyama et al, 1986; Peer and Margalit, 2006; Kornhuber et al, 2008; Kornhuber et al, 2011; Walker et al, 2011). Despite these observations, the mechanism(s) mediating the anticancer activity of these agents is unknown. To determine whether ASM inhibitors could be effective cancer therapeutics by inhibiting intracellular cholesterol transport, 42 ASM inhibitors were screened. ASM inhibitors were effective at killing cancer cells depending on genetic background. Melanoma cell lines harbouring activating BRAF mutations and loss of functional PTEN, required 2-5-fold lower concentrations of ASM inhibitors than normal skin cells or melanoma cells lacking these genetic alterations.

ASM inhibitor-mediated cell death was triggered by inhibition of cholesterol egress from lysosomes, which consequently deregulated cholesterol homoeostasis and impaired intracellular vesicle transport, cellular endocytosis as well as autophagic flux. The activity of AKT and STAT3 signalling pathways, two important cancer drivers that are downstream of receptor tyrosine kinase/ RAS signalling, were suppressed by FIASMAs. Analysis of the data from the LincsCloud database, supported these observations by showing significant similarities between cellular signatures of certain ASM inhibitors and genetic knockdown of RTK/RAS/PI3K pathway genes, KRAS, ERBB3 and AKT3.

Orally administered ASM inhibitors, perphenazine or fluphenazine, led to tumour inhibition but caused CNS-related sedation at concentrations required for anticancer activity. This was overcome by encapsulating the agents into nanoliposomes to modulate drug pharmacokinetics and potentially reduce bloodbrain-barrier permeability. Indeed, intravenous delivery of perphenazine nanoliposomes effectively enhanced the antitumour activity while reducing the negative sedative side effects. Since many ASM inhibitors are clinically viable drugs with wellestablished toxicity profiles, these discoveries could lead to the repurposing of these agents to function as anticancer cholesterol transport inhibitors by reformulating them within nanoparticles.

\section{MATERIALS AND METHODS}

Cell lines and plasmids. Metastatic melanoma cell line UACC 903 was provided by Dr Mark Nelson (University of Arizona); MelJuSo cell line was provided by Dr Judith Johnson (University of Munich); human fibroblast cell line (FF2441) and human foreskin keratinocytes (HFK) were provided by Dr Craig Myers (Penn State College of Medicine); FC-0023 epidermal melanocytes were purchased from Lifeline Cell Technologies (Frederick, MD, USA); 451Lu, 451LuR cell lines were provided by Dr Xiaowei Xu (University of Pennsylvania); C8161.Cl9 cell line was provided by Dr Danny Welch (University of Kansas) and all other melanoma cell lines were provided by Dr Herlyn (Wistar Institute). Wild-type and BAX-nockout HCT116 human colon cancer cell lines were provided by Dr Wafik El-Deiry (Penn State College of Medicine). Melanoma cell lines and FF2441 fibroblast cell line were maintained in DMEM (Invitrogen, Carlsbad, CA, USA) supplemented with $1 \%$ GlutaMAX (Thermo Fisher, Waltham, MA, USA) and $10 \%$ FBS (GE Healthcare, Chicago, IL, USA). HFK and FC0023 cells were grown in Epilife Medium with Human Keratinocyte and Melanocyte Growth Supplement (Thermo Fisher), respectively. Melanoma cell lines were periodically monitored for genotypic characteristics, phenotypic behaviour and tumourigenic potential to confirm cell line identity. GFPtagged LC3B expressing UACC 903 cell line was generated using the pBABE-puro mCherry-EGFP-LC3B plasmid (Addgene plasmid \#22418; Cambridge, MA, USA) (N’Diaye et al, 2009).

Microarray data. Microarray data files (cel files) that contain the expression profile of MCF7 cells treated with different compounds and at least three associated vehicle controls were downloaded from the Connectivity Map project website (www.broadinstitute.org/cmap/; see Supplementary Materials and Methods Section for the C-Map IDs). ArrayStar software (v 12.2, Dnastar, Madison, WI, USA) was used to analyse the data. For the details of microarray analysis please see the Supplementary Materials and Methods Section.

Drug treatment conditions and assessment of $\mathbf{I C}_{\mathbf{5 0}}$. The viability of cells following compound (see Supplementary Materials and Methods Section for compound sources) or liposome treatments was measured using the MTS assay (Promega, Madison, WI, USA) as described previously (Gowda et al, 2014). Briefly, cells were plated in 96-well plates, grown to $70-80 \%$ confluency, and treated with either vehicle or varying concentrations of experimental agents. $24 \mathrm{~h}$ later, the MTS assay was performed and $\mathrm{IC}_{50}$ estimated for each compound using GraphPad Prism (GraphPad Software, La Jolla, CA, USA). In co-treatment studies, compounds were added simultaneously.

Mitochondrial membrane potential (MMP) and caspase-dependence assays. MMP of cells was measured using the TMRE MMP Assay Kit (Abcam, Cambridge, MA, USA). Caspase-3/7 activity was measured using a fluorogenic substrate Ac-DEVD-AFC using the protocol for the Caspase-3 Inhibitor Screening Assay Kit (Merck, Billerica, MA, USA). Caspase-dependent cell death was assessed by pre-treatment of cells with pan-caspase inhibitor $\mathrm{z}$-VAD-fmk $\left(20 \mu \mathrm{moll}^{-1}\right)$ for $1 \mathrm{~h}$ before drug treatments. $24 \mathrm{~h}$ after treatments, cell viability was measured by MTS assay.

Cholesterol localisation assay. Localisation of intracellular cholesterol was detected through Filipin-III staining of cells using the Cayman's Cholesterol Cell-Based Detection Assay Kit (Cayman Chemical, Ann Arbor, MI, USA). Lysosomal/late endosomal localisation of cholesterol was assessed by co-localisation of LAMP1-RFP and Filipin-III signals using iVision software (BioVision Technologies, Chester Springs, PA, USA). An RFPtagged LAMP1 expressing UACC 903 cell line was created using 
LAMP1-mRFP-FLAG plasmid (Addgene plasmid \#34611) (Zoncu et al, 2011). Images were taken at $\times 1000$ magnification.

Evaluation of cellular endocytosis. The endocytic capacity of cells was measured using Alexa Fluor-488-conjugated transferrin protein (Thermo Fisher) as described previously (Kuzu et al, 2014). Cells were plated into chamber slides (or six-well plates for flow cytometry analysis) and treated with compounds for 3-4 h. Cells were then incubated for $30 \mathrm{~min}$ with Alexa Fluor 488conjugated transferrin protein $\left(5 \mu \mathrm{g} \mathrm{ml}^{-1}\right)$, washed with phosphate-buffered saline and either fixed with $4 \%$ paraformaldehyde for fluorescence microscopy analysis or trypsinised, and collected for flow cytometry analysis.

Western blot analysis. One to two million cells were plated in $100 \mathrm{~mm}$ dishes and grown to $75-90 \%$ confluency. After drug treatments for various times, cells were harvested in RIPA buffer containing protease and phosphatase inhibitors (Thermo Fisher). BCA Assay (Thermo Fisher) was used for protein quantification and $30 \mu \mathrm{g}$ of protein was loaded per lane onto NuPage gels (Life Technologies, Carlsbad, CA, USA). Following electrophoresis, proteins were transferred to PVDF membrane and blots probed with antibodies according to supplier's recommendations (detailed antibody information provided in Supplementary Materials and Methods Section). ECL detection (Thermo Fisher) was used to visualise immunoblots.

Animal studies. All animal experiments were undertaken according to protocols approved by the Institutional Animal Care and Use Committee at The Pennsylvania State University. Effects of the compounds on xenografted tumour growth were measured in athymic-Foxn 1 - / - (nude) mice (Harlan Laboratories, Indianapolis, IN, USA). Briefly, one million melanoma cells were injected subcutaneously above both the left and right rib cages of 4-6-weekold female mice. Six-days post injection, when the tumour size was $\sim 100 \mathrm{~mm}^{3}$, animals were randomly separated into groups (four animals/group). For oral administration, perphenazine and nortriptyline were dissolved in glyceryl trioctanoate, while fluphenazine and desipramine were dissolved in water and administered via oral gavage (100 ul per treatment). Nortriptyline and desipramine were administered on alternate days while perphenazine and fluphenazine were administered at 4-day intervals due to the sedation-associated symptoms. Liposomal formulation of perphenazine was administered via intravenous (tail-vein) injection on alternate days. Liposomes were prepared as $5 \mathrm{mg} \mathrm{ml}^{-1}$ drug concentration. Liposomes were diluted with $0.9 \%$ saline and injections were performed as $200 \mathrm{ul}$ per injection. Body weight and tumour dimensions were measured on treatment days. At the end of experiments, blood was collected and serum was separated and analysed for blood markers of major organ function and toxicity at The Pennsylvania State University Animal Resource Core. Major organs of the animals were formalin fixed and paraffin embedded to examine changes in cell morphology and tissue organisation following haematoxylin and eosin (H\&E) staining.

Statistical analysis. Statistical analyses were performed using the unpaired Student $t$-test. A $P$-value $<0.05$ was considered statistically significant. ${ }^{\star} P<0.05 ;{ }^{\star *} P<0.01 ;{ }^{* *} P<0.001$. Unless otherwise noted, error bars represent s.e.m.

\section{RESULTS}

Genetic knockdown of ASM inhibits intracellular cholesterol transport and decreases cancer cell viability. To determine whether siRNA-mediated inhibition SMPD1 expression would inhibit intracellular cholesterol transport and alter the viability of cancer cell lines, two siRNAs targeting SMPD1 were transfected into melanoma cells. As assessed by qRT-PCR, SMPD1 expression was effectively reduced to $10 \%$ of that observed for the mock transfection control (Supplementary Figure 1A). Mimicking the Niemann-Pick Disease, knockdown of the SMPD1 inhibited lysosomal cholesterol export as determined by Fillipin-III staining of the accumulated lysosomal cholesterol (Figure 1A). Furthermore, inhibition of the SMPD1 expression reduced the viability of both UACC 903 and $1205 \mathrm{Lu}$ melanoma cell lines to 35\% of that observed for the controls suggesting that ASM could be a potential therapeutic target (Figure 1B).

Identifying ASM inhibitors with anticancer activity. To determine whether ASM inhibitors could promote cancer cell death by inhibiting intracellular cholesterol transport, a library of 42 ASM inhibitors were screened (Kornhuber et al, 2008; Kornhuber et al, 2011). All of these agents have been reported to decrease in ASM activity by 70-90\% (Kornhuber et al, 2008; Kornhuber et al, 2011). Leelamine and U18666A, two previously identified cholesterol transport inhibitors, were used as positive controls. Killing efficacy of each ASM inhibitor was tested on UACC 903 and $1205 \mathrm{Lu}$ melanoma cells and compared to normal FF2441 skin fibroblasts. Both melanoma cell lines were killed by ASM inhibitors with significantly lower $\mathrm{IC}_{50}$ values (paired $t$-test, $P<0.001$ ) compared to fibroblasts (Figure $1 \mathrm{C}$ and Supplementary Table 1). Average $\mathrm{IC}_{50}$ values for the melanoma cell lines were threefold lower than for the normal fibroblasts. Since the ASM inhibitors killed cancer cells more effectively than normal cells the chemotherapeutic utility of these agents was examined next.

Accumulation of ASM inhibitors in lysosomes was required for killing cancer cells. To identify the mechanism by which ASM inhibitors killed cancer cells, five compounds (desipramine, flupenthixol, fluphenazine, nortriptyline and perphenazine), killing melanoma cells at low $\mathrm{IC}_{50}$ values, were investigated. These lysosomotropic compounds have been reported to inhibit ASM by disrupting the electrostatic attraction between the negatively charged Bis-monoacyl glycerophosphate and the positively charged ASM protein (Kornhuber et al, 2011). Similar to other lysosomotropic compounds, the ASM inhibitors had pKa values of 7-11 and induced cellular vacuolisation following treatment (Supplementary Table 1 and Supplementary Figures 1B-C) (Nadanaciva et al, 2011). UACC 903 cells were 4-6-fold more sensitive to these ASM inhibitors compared to normal fibroblasts (Figure 1D). To assess whether the lysosomotropic accumulation of these ASM inhibitors was required for induction of cancer cell death, cells were cotreated with a vacuolar-ATPase (v-ATPase) inhibitor, BafilomycinA1 (BafA1). The v-ATPase functions as a proton pump to ensure the acidity of acidic organelles, which is the driving force underlying lysosomotropic drug accumulation. Therefore, v-ATPase inhibitors, such as BafA1, reduce the uptake of lysosomotropic compounds (Marceau et al, 2012). BafAl treatment inhibited the lysosomotropic accumulation of the ASM inhibitors as observed by the total loss of cellular vacuolisation induced by these agents (Supplementary Figure 1C). Furthermore, Bafilomycin-A1 co-treatment effectively suppressed cell death induced by these agents suggesting that the lysosomotropic property of the ASM inhibitors was essential for anticancer activity (Figure 1E and Supplementary Table 1).

ASM inhibitors disrupt cholesterol transport from late endosomal/lysosomal cell compartments mediating cancer cell death. Leelamine-mediated cell death involves inhibition of cholesterol egress from lysosomes (Kuzu et al, 2014). To determine whether ASM inhibitors acted in a similar manner, intracellular cholesterol levels were measured by Filipin-III staining. After $6 \mathrm{~h}$, ASM inhibitor treatment promoted intracellular cholesterol accumulation in a manner similar to that occurring with positive controls, leelamine and U18666A (Figure 1F). Cholesterol accumulation inside the late endosomal/lysosomal cell compartments was 



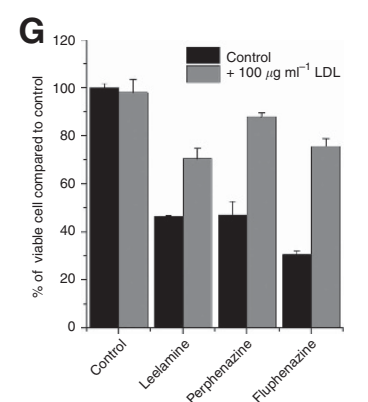

H

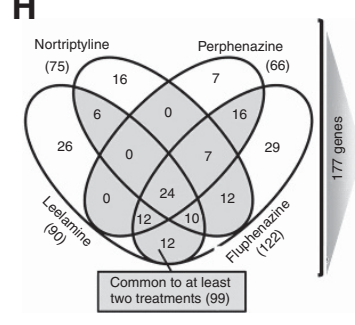

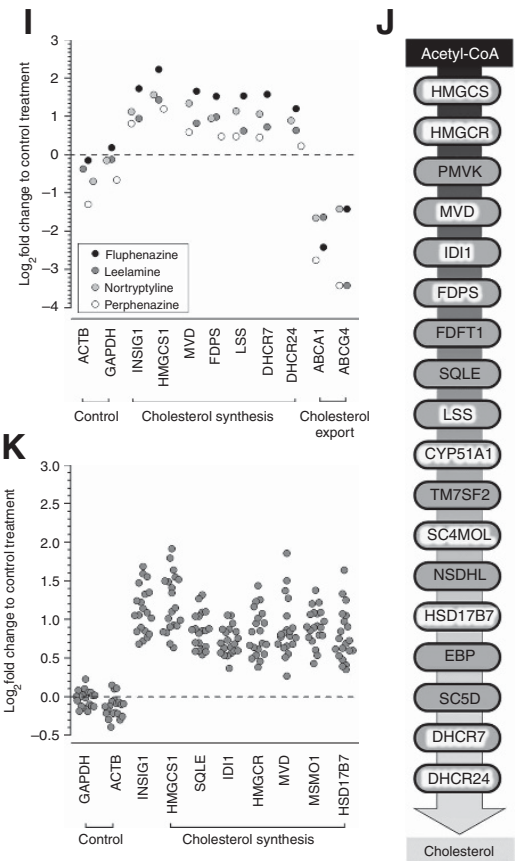

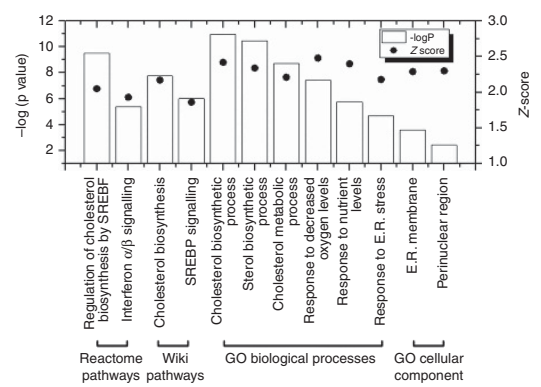

Figure 1. ASM inhibitors induce melanoma-specific cell death by inhibiting intracellular cholesterol transport. (A) fluorescence microscopy of intracellular cholesterol localisation following knockdown of SMPD1 (ASM1) as detected by Filipin-III staining (arrows show accumulated cholesterol); (B) the viability of UACC 903 and 1205 Lu melanoma cells following knockdown of SMPD1; (C) IC 50 values of various melanoma cell lines and FF2441 fibroblasts treated with ASM inhibitors. Dose-response curves were drawn in OriginPro (OriginLab) using Levenberg Marquardt algorithm; (D) viability of UACC 903 and FF2441 cells following $24 \mathrm{~h}$ of treatment with increasing concentrations of ASM inhibitors; (E) viability of melanoma cells treated with various ASM inhibitors in the absence or presence of v-ATPase inhibitor, Bafilomycin-A1; (F) intracellular cholesterol localisation following leelamine, U18666A or ASM inhibitor treatments as detected by Filipin-III staining. (lower) Co-localisation of RFP-tagged lysosomal LAMP1 protein with cholesterol; (G) LDL treatment protects UACC 903 cells from ASM inhibitor-mediated cell death; (H) Venn diagram showing number of significantly altered genes identified by RNA-sequencing of UACC 903 cells treated with ASM inhibitors (left); and enrichment analysis of significantly altered 177 genes; (I) expression level of cholesterol synthesis genes following ASM treatment as detected by RNAsequencing; $(\mathrm{J})$ cholesterol synthesis pathway. White highlighted genes were identified as significantly deregulated by RNA-sequencing; (K) distribution of log-2-fold change in expression levels of cholesterol synthesis genes identified by microarray analysis following treatment of MCF7 cells with ASM inhibitors.

observed as co-localisation of RFP-tagged LAMP1 (lysosomeassociated membrane glycoprotein-1) with accumulating cholesterol (Figure 1F, bottom). At the subcellular level, leelamine-mediated lysosomal cholesterol accumulation-induced the formation of lipofuscin-like lipid-filled lysosomes (Kuzu et al, 2014). Similarly, transmission electron micrographs of UACC 903 cells treated with ASM inhibitors showed lipid-filled lysosomes further confirming the induction of lysosomal cholesterol accumulation by ASM inhibitors (Supplementary Figure 1D). To determine whether cell death initiated by ASM inhibitors could be reversed by restoring cellular cholesterol levels, cells were supplemented with excess amounts of LDL-cholesterol which increased intracellular cholesterol by alternate LDL internalisation processes (Zhao et al, 2006). As predicted, supplementation of LDL-cholesterol overrode the inhibition of lysosomal cholesterol egress and protected UACC 903 cells from cell death induced by the ASM inhibitors (Figure 1G). The protective effect of
LDL-cholesterol was dose-dependent and also occurred with $1205 \mathrm{Lu}$ cells (Supplementary Figure 1E). Thus, ASM inhibitors disrupted intracellular cholesterol transport.

ASM inhibitors deregulated cholesterol homoeostasis. Inhibition of intracellular cholesterol transport was predicted to deregulate cholesterol homoeostasis. To identify the signalling cascades altered by ASM inhibitors, genome-wide mRNA sequencing experiments were performed on perphenazine, fluphenazine, nortriptyline or leelamine treated UACC 903 cells. In total, 177 genes were significantly deregulated by ASM inhibitors (Figure $1 \mathrm{H}$ and Supplementary Table 2). Ninety-nine of these alterations were common to at least two out of the four treatments (Figure $1 \mathrm{H}$ ). Enrichment analysis of the altered genes to identify biological processes, pathways and transcription factors affected by the compound showed significant deregulation of cholesterol homoeostasis (Figure $1 \mathrm{H}$, right and Table $1 \mathrm{~A}$ ). The binding site for the 
Table 1. Geneset enrichment analysis

\begin{tabular}{|c|c|c|c|}
\hline Pathway & $P$-value & Z-score & Tool \\
\hline \multicolumn{4}{|l|}{ (A) RNA-Seq enrichment analysis } \\
\hline $\begin{array}{l}\text { Regulation of cholesterol biosynthesis } \\
\text { by SREBF }\end{array}$ & $3.10 \mathrm{E}-10$ & -2.05 & Reactome \\
\hline Interferon $\alpha / \beta$-signalling & $4.10 E-06$ & -1.93 & Reactome \\
\hline Cholesterol biosynthetic process & $1.09 E-11$ & -2.42 & GOBP \\
\hline Cholesterol metabolic process & $1.87 E-09$ & -2.21 & GOBP \\
\hline Response to decreased oxygen levels & $3.78 \mathrm{E}-08$ & -2.48 & GOBP \\
\hline Response to nutrient levels & $1.75 E-06$ & -2.4 & GOBP \\
\hline $\begin{array}{l}\text { Response to endoplasmic reticulum } \\
\text { stress }\end{array}$ & $2.03 E-05$ & -2.18 & GOBP \\
\hline Endoplasmic reticulum membrane & $2.62 \mathrm{E}-04$ & -2.29 & GOCC \\
\hline Perinuclear region of cytoplasm & $3.86 \mathrm{E}-03$ & -2.3 & GOCC \\
\hline SREBF1 & $3.41 \mathrm{E}-08$ & -1.88 & ENCODE \\
\hline \multicolumn{4}{|c|}{ (B) RNA-Seq groupwise comparison enrichment analysis } \\
\hline Cholesterol biosynthetic process & $7.95 \mathrm{E}-13$ & -2.41 & GOBP \\
\hline Cholesterol metabolic process & $5.49 E-13$ & -2.21 & GOBP \\
\hline Steroid biosynthetic process & $1.78 \mathrm{E}-07$ & -2.22 & GOBP \\
\hline ER-nucleus signalling pathway & $3.00 E-07$ & -2.19 & GOBP \\
\hline Cellular response to hypoxia & $4.97 \mathrm{E}-07$ & -2.24 & GOBP \\
\hline Response to nutrient levels & $2.04 E-06$ & -2.42 & GOBP \\
\hline Isoprenoid biosynthetic process & $8.76 E-06$ & -2.71 & GOBP \\
\hline $\begin{array}{l}\text { Response to endoplasmic reticulum } \\
\text { stress }\end{array}$ & $3.79 E-06$ & -2.22 & GOBP \\
\hline $\begin{array}{l}\text { Regulation of cholesterol biosynthesis } \\
\text { by SREBP }\end{array}$ & $3.12 \mathrm{E}-09$ & -2.05 & Reactome \\
\hline $\begin{array}{l}\text { Activation of gene expression by } \\
\text { SREBF (SREBP) }\end{array}$ & $1.40 \mathrm{E}-05$ & -2.06 & Reactome \\
\hline UPR & $2.15 E-04$ & -1.93 & Reactome \\
\hline
\end{tabular}

(C) Microarray pairwise comparison enrichment analysis

\begin{tabular}{l|c|c|c}
\hline $\begin{array}{l}\text { Regulation of cholesterol biosynthesis } \\
\text { by SREBP }\end{array}$ & $3.65 \mathrm{E}-07$ & -2.05 & Reactome \\
$\begin{array}{l}\text { PERK regulates gene expression } \\
\text { (ER stress) }\end{array}$ & $5.16 \mathrm{E}-06$ & -2.14 & Reactome \\
UPR & $4.33 \mathrm{E}-06$ & -1.94 & Reactome \\
Cholesterol biosynthetic process & $1.19 \mathrm{E}-10$ & -2.42 & GOBP \\
$\begin{array}{l}\text { Response to nutrient levels } \\
\text { Response to endoplasmic reticulum }\end{array}$ & $3.27 \mathrm{E}-09$ & -2.45 & GOBP \\
stress & $2.13 \mathrm{E}-09$ & -2.25 & GOBP \\
$\begin{array}{l}\text { Cholesterol metabolic process } \\
\text { Endoplasmic reticulum membrane }\end{array}$ & $1.85 \mathrm{E}-09$ & -2.2 & GOBP \\
Perinuclear region of cytoplasm & $1.02 \mathrm{E}-07$ & -2.29 & GOCC \\
\hline
\end{tabular}

(D) Microarray groupwise comparison enrichment analysis \begin{tabular}{|l|l|l|l|}
\hline Regulation of cholesterol biosynthesis & $1.91 \mathrm{E}-12$ & -2.05 & REACTOME
\end{tabular} by SREBP

UPR

PERK regulates gene expression (ER stress)

Cholesterol biosynthetic process

Response to endoplasmic reticulum

stress

Cholesterol metabolic process

ER-nucleus signalling pathway

Autophagy

ER to Golgi vesicle-mediated

transport

Response to starvation

Intrinsic apoptotic signalling pathway

in response to ER stress

Abbreviations: $E R=$ endoplasmic reticulum; $G O B P=$ Gene Ontology Biological Process,

$\mathrm{GOCC}=$ Gene Ontology Cellular Component; UPR $=$ unfolded protein response.

transcription factor SREBF, the major regulator of the cholesterol homoeostasis, was significantly enriched among the promoters of the 177 genes $\left(P\right.$-Value: $3.1 \times 10^{-10}$; $z$-score: -2.05$)$ (Table $\left.1 \mathrm{~A}\right)$. Several genes involved in cholesterol biosynthesis were upregulated while cholesterol export genes were downregulated (Figure 1I). As an alternative approach to analyse the RNA-Seq data, cholesterol transport inhibitors were grouped together and compared to the control group using the differential expression analysis tool (DeSeq tool) (Anders and Huber, 2010). Eleven out of the 18 genes in the cholesterol synthesis pathway were among the most significantly altered 300 genes (Figure 1J and Supplementary Table 3) (Anders and Huber, 2010). Cholesterol biosynthetic $\left(P\right.$-value: $7.95 \times 10^{-13}$; $z$-score: -2.41$)$ and metabolic $\left(P\right.$-value: $5.49 \times 10^{-13}$; $z$-score: -2.21) processes were significantly altered with the ASM inhibitors (Table 1B).

To confirm that ASM inhibitors deregulate cholesterol homoeostasis in a second cancer type, gene expression profiles of MCF7 breast cancer cells treated independently with 20 different ASM inhibitors and respective vehicle controls were downloaded from the Connectivity Map database (c-Map) and analysed using the ArrayStar software (Lamb et al, 2006). Comparison of each treatment to its respective control showed that 41 genes were significantly deregulated by at least 10 out of the 20 compounds (Supplementary Table 4). Cholesterol biosynthesis ( $P$-value: $1.19 \times 10^{-10} ; \quad z$-score: -2.42$)$ and metabolism ( $P$-value: $1.85 \times 10^{-9} ; z$-score: -2.2$)$ were significantly enriched in this set of 'commonly deregulated genes' (Table 1C). INSIG1, a cholesterol sensor in the endoplasmic reticulum (ER), was upregulated by all 20 compounds, and five cholesterol synthesis genes (HMGCR, HMGCS1, SQLE, MVD and SC4MOL) were among the 41 commonly deregulated genes (Supplementary Table 4). As a negative control, several randomly chosen compounds from the c-Map database were selected; however, no deregulation of cholesterol synthesis/metabolism pathways was observed (data not shown).

As a confirmatory approach, all 20 ASM inhibitors were grouped together and compared with the control group, identifying 272 significantly altered probes representing 213 individual genes, at a $99 \%$ confidence level with a moderated $t$-test (Supplementary Table 5). Twenty-six out of the 59 (44\%) proteins in the Gene Ontology (GO) category of 'Cholesterol biosynthetic process' were significantly deregulated by the ASM inhibitors ( $P$-value: $5.49 \times 10^{-16} ; \quad z$-score: -2.42 ) (Table 1D). Many cholesterol synthesis (e.g., HMGCS1, SQLE, IDI1) and homoeostasis (e.g., INSIG1) genes were 2-4-fold upregulated by the ASM inhibitors (Figure 1K). Niemann-surya Pick disease, type C1 (NPC1) protein, which exports cholesterol from lysosomes was also upregulated, likely as a response to the inhibition of cholesterol transport from lysosomes (Supplementary Table 5). These results suggested that inhibition of cholesterol egress from lysosomes by ASM inhibitors deregulated intracellular cholesterol homoeostasis. Furthermore, upregulation of the cholesterol biosynthesis genes indicated a cellular response to decreased levels of cholesterol in the ER suggesting that lysosomal cholesterol was invisible to the cholesterol regulatory pathways of the cancer cells. In NiemannPick disease, impaired cholesterol trafficking to the ER also upregulated cholesterol synthesis despite cholesterol accumulation in lysosomes (Peake and Vance, 2010), further supporting this possibility.

ASM inhibitors suppress xenografted melanoma tumour growth. To measure the chemotherapeutic potential of ASM inhibition, efficacies of perphenazine, nortriptyline and desipramine were tested on xenografted tumour development. Oral administration of perphenazine-reduced tumour growth by $60 \%$ whereas nortriptyline and desipramine led to $50 \%$ and $30 \%$ tumour inhibition, respectively (Figure 2A). Histological analyses of tumours harvested from perphenazine-treated animals showed cellular vacuolisation with a significant decrease in mitotic figure numbers (Figure $2 \mathrm{~B}$ and $\mathrm{C}$ ). Since, perphenazine had the greatest effect on tumour growth, this agent and a related ASM inhibitor, fluphenazine, were subsequently tested for inhibiting UACC 903, $1205 \mathrm{Lu}$ and A2058 tumour development. Oral administration of perphenazine at $50 \mathrm{mg} \mathrm{kg}^{-1}$ or fluphenazine at $25 \mathrm{mg} \mathrm{kg}^{-1}$ at 4day intervals led to a $40-60 \%$ decrease in tumour development (Figure 2D-H). Tumour weights harvested from the drug-treated 


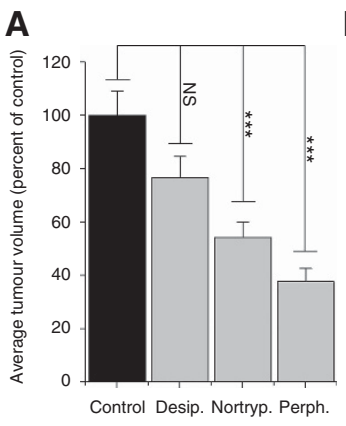

B

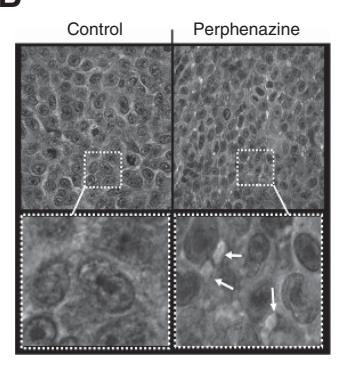

C

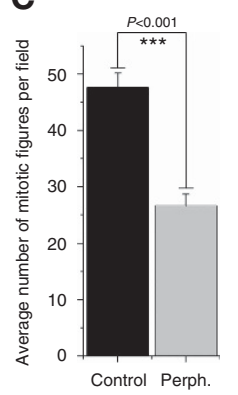

D

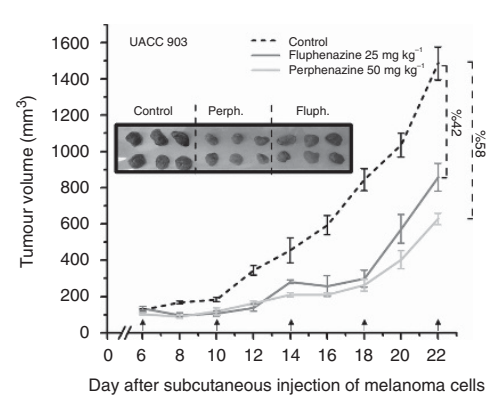

E

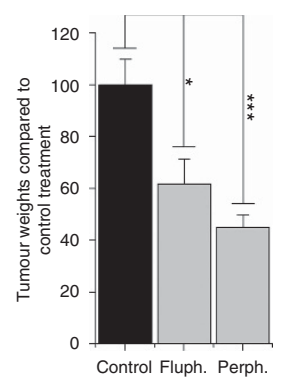

F



G

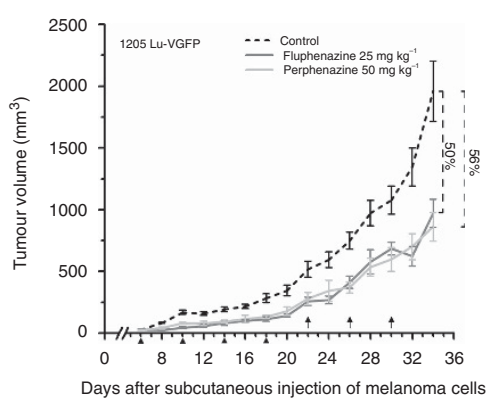

H

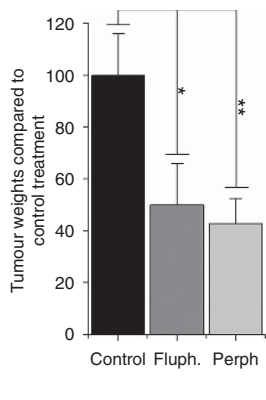

I

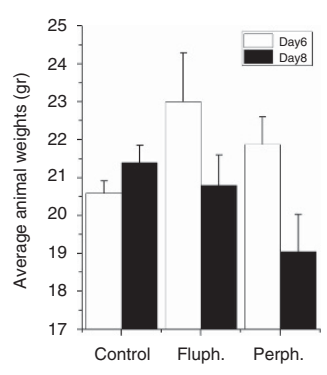

Figure 2. Efficacy of cholesterol transport inhibitors on xenografted melanoma tumour development. (A) bar graph representing the effect of oral administration of desipramine, nortriptyline and perphenazine on xenografted UACC 903 melanoma tumour growth at day 22; (B) H\&E stained tumour sections showing vacuolisation of tumours harvested from animals treated with perphenazine; (C) bar graph showing average number of mitotic figures identified in H\&E stained sections of tumours harvested from perphenazine or vehicle-treated mice; (D-H) growth kinetics or tumour weights of UACC 903,1205 Lu and A2058 xenografted tumours following oral administration of fluphenazine (25 mg kg ${ }^{-1}$ ) or perphenazine $\left(50 \mathrm{mg} \mathrm{kg}^{-1}\right.$ ). Image (inset in D) showing UACC 903 tumours harvested at the end of the experiment. (E and $\left.\mathbf{H}\right)$ bar graphs showing tumour weight percentages compared to vehicle-treated animals, harvested from UACC 903 and A2058 xenografts, respectively; (I) bar graph showing the weight loss of mice with UACC 903 xenografts 2 days after drug treatments. ${ }^{\star} P<0.05$; ${ }^{\star \star} P<0.01 ;{ }^{\star \star \star} P<0.001$.

animals at the end of treatment were $40-60 \%$ lower than control groups (Figure 2E and $\mathrm{H}$ ).

At the end of the perphenazine treatment, blood serum was collected and analysed for blood biomarkers indicative of major organ toxicity. Compared to controls, total bilirubin levels were significantly higher in perphenazine-treated animals, likely due to haemolytic anaemia, a known side effect of phenothiazine antipsychotics, such as perphenazine (Supplementary Table 6) (Ohlow and Moosmann, 2011). Histological analysis of vital organs showed no alteration in cell morphology or tissue architecture (Supplementary Figure 2D). However, both perphenazine and fluphenazine caused CNS-related side effects limiting the maximum drug dosage that could be administered to animals. Thirty to sixty minutes after oral administration, animals became sedated, which persisted for $>24 \mathrm{~h}$, limiting feeding and causing a $10 \%$ loss of body weight (Figure 2I and Supplementary Figure 2A-C). Thus, administration of certain clinically used ASM inhibitors at doses causing an anticancer effect was limited due to sedative CNSrelated effects, necessitating reformulation for use in cancer therapy.

Nanoliposomal encapsulation of perphenazine reduced side effects while enhancing chemotherapeutic efficacy. Liposomal encapsulation of the CNS-active ASM inhibitors was hypothesised to able to decrease CNS-related side effects by reducing bloodbrain-barrier permeability. This approach was also predicted to increase efficacy by prolonging the drug circulation lifetime, and through the enhanced permeability and retention (EPR) effect (Greish, 2007). Therefore, perphenazine was encapsulated into nanoliposomes having a neutral charge (in saline) and an average size of $70 \mathrm{~nm}$. Encapsulation efficiency was $66 \% \pm 3$ (s.e.m.) with a drug to lipid ratio of $0.2(\mathrm{~m} / \mathrm{m})$. Nanoliposomal perphenazine was as effective as the free drug at killing cultured cancer cells and was stable at $4{ }^{\circ} \mathrm{C}$ for 20 weeks (Supplementary Table 7). Encapsulated perphenazine was released from liposomes at a rate of $2.6 \%$ per hour over a 24-h time period (Supplementary Figure 3A). Furthermore, nanoliposomal encapsulation eliminated the haemolytic activity occurring with orally administered perphenazine suggesting that this approach could also lessen haemolytic anaemia associated with high doses of this drug (Supplementary Figure 3B).

To determine whether nanoliposomal encapsulation of perphenazine decreased CNS-related sedative effects, Swiss-Webster mice were examined using video surveillance following treatment. Control mice spent approximately $40 \%$ of the day awake and motile, which decreased to $6 \%$ when $50 \mathrm{mg} \mathrm{kg}^{-1}$ perphenazine was administered orally $\left(P=5.05 \times 10^{-15}\right)$ (Figure $3 \mathrm{~A}$ and $\mathrm{B}$ ). In contrast, mice treated intravenously with nanoliposomal perphenazine at $15 \mathrm{mg} \mathrm{kg}^{-1}$ were awake and active $30 \%$ of the day, which was a significant improvement compared to oral treatment $\left(P=2.8 \times 10^{-10}\right)$. A dose-matched oral control of $15 \mathrm{mg} \mathrm{kg}^{-1}$ perphenazine had a slightly greater sedative effect compared to liposomal treatment $(P=0.037)$ but caused body weight loss following treatment for 2 days (Figure $3 \mathrm{~A}-\mathrm{C}$ ). Nanoliposomal perphenazine treated animals did not lose weight compared to a $10 \%$ loss observed following oral treatments (Figure 3C). These results suggest that nanoliposomal encapsulation decreases CNS-associated sedative side effects of perphenazine.

Nanoliposomal perphenazine was as effective as the free drug at killing cultured cancer cells, having an $\mathrm{IC}_{50}$ of 10 um for UACC 903 melanoma cells (Figure 3D). Intravenous administration of $15 \mathrm{mg} \mathrm{kg}^{-1}$ perphenazine nanoliposomes on alternate days led to 60 and 70\% decrease in UACC 903 and $1205 \mathrm{Lu}$ tumour development, respectively (Figure $3 \mathrm{E}-\mathrm{G}$ ). In contrast, the free drug was ineffective at inhibiting UACC 903 tumour development 

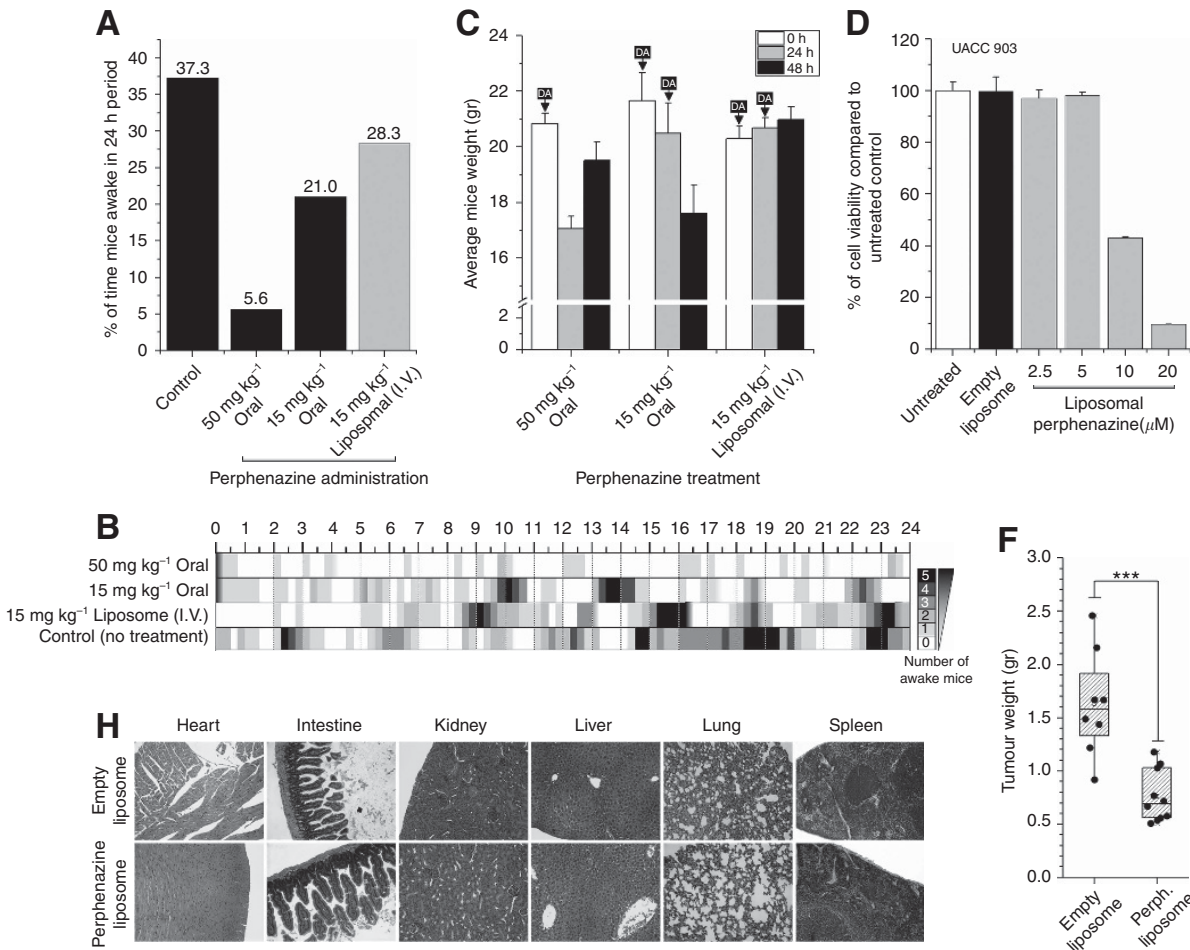

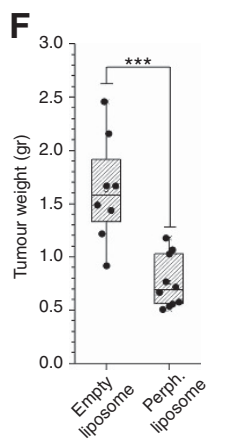





Figure 3. Liposomal administration of perphenazine enhanced therapeutic activity while decreasing sedative side effects. (A) bar graph showing activity of mice following oral or intravenous liposomal administration of perphenazine; (B) sleep behaviour of mice treated with perphenazine; (C) bar graph showing body weight change in Swiss Webster mice following oral or intravenous liposomal administration of perphenazine (DA: Drug administration); (D) efficacy of liposomal perphenazine on cultured UACC 903 melanoma cells survival; (E and G) growth kinetics of UACC 903 and 1205 Lu xenografted tumours following intravenous administration of $15 \mathrm{mg} \mathrm{kg}^{-1}$ liposomal perphenazine. Inserts in each graph show average mice weight during the treatment period; (F) distribution of tumour weights harvested from mice treated with empty or perphenazine encapsulated liposomes; $(\mathbf{H}) \mathrm{H} \& \mathrm{E}$ stained vital organ sections of mice treated with empty or perphenazine encapsulated liposomes. ${ }^{* \star *} P<0.001$.

at 12.5 or $25 \mathrm{mg} \mathrm{kg}^{-1}$ concentrations (Supplementary Figure 3C). Weights of the tumours harvested from perphenazine nanoliposome treated xenografts were 2-3-fold lower than the vehicletreated control group (Figure $3 \mathrm{~F}$ ). No significant weight loss was observed and all serum markers indicative of major organ toxicity were comparable to controls (Figure 3E and G; Supplementary Table 6). Histopathological analysis of major organs showed no differences between experimental and control groups (Figure $3 \mathrm{H}$ ). Thus, nanoliposomal encapsulation of CNS-active ASM cholesterol transport inhibitors might provide a novel approach for decreasing CNS-related side effects while enhancing the anticancer activity of the compound.

Inhibition of intracellular cholesterol transport blocks autophagic flux. Disruption of intracellular cholesterol transport has been shown to inhibit autophagic flux (Kuzu et al, 2014). Analysis of microarray data from the c-Map database also suggested that ASM inhibitors deregulate autophagic processes (Table 1C). To determine whether ASM inhibitors would deregulate autophagic flux, levels of the autophagosome marker, LC3B, and autophagic flux marker, p62/SQSTM1, were examined by western blotting. Nortriptyline, perphenazine or fluphenazine-treated UACC 903 cells, led to dose-dependent accumulation of LC3B and p62 proteins (Figure 4A). Accumulation of LC3B was also observed through fluorescence microscopy of GFP-tagged LC3B expressing UACC 903 cells (Figure 4B). Thus ASM inhibitors suppressed autophagic flux causing aggregation of autophagosomes in a manner similar to that occurring with the cholesterol transport inhibitor leelamine (Kuzu et al, 2014).

Inhibition of intracellular cholesterol transport by ASM inhibitors suppressed cellular endocytosis. Targeting cholesterol transport using leelamine or disruption of this process in Niemann-Pick disease leads to inhibition of cellular endocytosis (Peake and Vance, 2010; Kuzu et al, 2014). Hence, the effect of ASM inhibitors on cellular endocytosis was examined by measuring uptake of Alexa Fluor-conjugated transferrin. Transferrin is typically internalised into early endosomes through clathrinmediated endocytosis, which serves as the major pathway for uptake of receptor-ligand complexes (Liu et al, 2010). Uptake of Alexa Fluor-conjugated transferrin protein was measured by fluorescence microscopy and flow cytometry (Kuzu et al, 2014). In contrast to the vehicle-treated control group, cells treated with ASM inhibitors did not take up transferrin, suggesting that these compounds inhibit cellular endocytosis (Figure 4C). Flow cytometric quantitation of transferrin uptake demonstrated a dosedependent inhibition of endocytosis (Figure 4D). Cellular endocytosis is critical for cancer cell survival as many oncogenic signals are initiated by membrane receptors that are regulated by endocytosis (Polo et al, 2004).

ASM inhibitors deregulated intracellular vesicle trafficking. Transport of LDL-derived cholesterol from the lysosomes to the ER involves the trans-Golgi network (TGN) (Urano et al, 2008). In Niemann-Pick disease, inhibition of cholesterol egress from lysosomes depletes cholesterol levels both in TGN and ER (Garver et al, 2002; Urano et al, 2008; Peake and Vance, 2010). Lower cholesterol levels in these organelles disrupts efficient ER to Golgi vesicle transport (Ridsdale et al, 2006). Enrichment analysis of the RNA-Seq data suggested increased ER stress and disrupted ER to Golgi vesicle-mediated transport following treatment with ASM inhibitors (Table 1). To confirm the cellular consequences of ASM inhibitors on intracellular vesicle trafficking, the perturbation 



$\mathbf{F}$



C
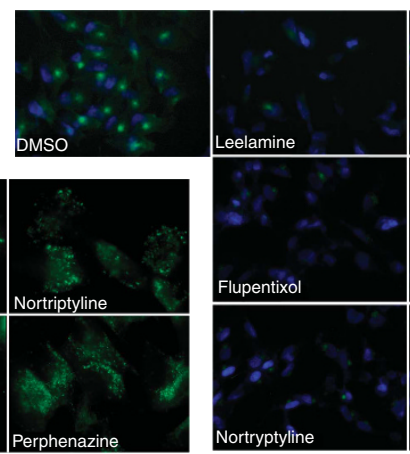

G

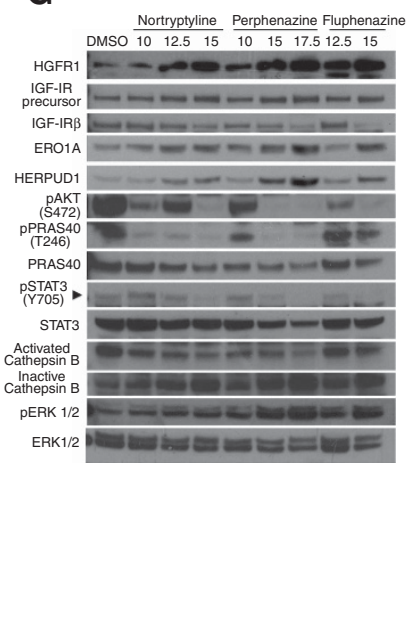

D



H

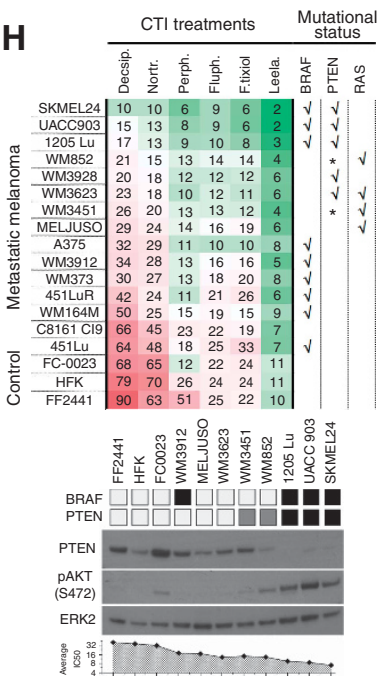

Figure 4. ASM inhibitors disrupt autophagic flux and cellular endocytosis leading to inhibition of oncogenic signalling. (A) Western blot analyses showing LC3B and p62/SOSTM1 levels as a marker of autophagic flux in UACC 903 cells; (B) fluorescence microscopy of GFP-tagged LC3B suggesting autophagosome accumulation in ASM inhibitor or Bafilomycin-A1 (positive control) treated UACC 903 cells; (C) fluorescence microscopy images showing endocytosis of Alexa Fluor-conjugated transferrin protein following treatment with vehicle (DMSO) or ASM inhibitors; (D) flow cytometry-based quantification of Alexa Fluor-conjugated transferrin endocytosis; (E) common genetic perturbations that were significantly linked to the cholesterol transport inhibitors in the Lincscloud database (top), and gene enrichment analysis of the 56 genes that exhibit similar cellular signature to the CTI treatments (bottom). Numbers in top panel shows similarity scores between perturbations; KD: knockdown; OE: overexpression; (F) immunofluorescence staining shows perinuclear accumulation of IGF1R protein; (G) western blots of UACC 903 cells treated with increasing concentrations of nortriptyline, perphenazine or fluphenazine; $(\mathrm{H})$ approximate $\mathrm{IC}_{50}$ values of various $\mathrm{CTI}$ agents for metastatic melanoma cell lines and normal skin cells suggesting increased sensitivity of mutant PTEN cells to these agents (top), western blots suggesting a correlation between AKT activity and CTI sensitivity of melanoma cell lines (bottom). ${ }^{*}<0.05$.

signature similarity data in Lincscloud database was analysed (lincscloud.org). This database contains cellular signatures obtained from various cellular perturbations following chemical treatments, gene knockdown or overexpression studies, enabling comparison of similarities between different perturbations over multiple cell lines. Signature data for 32 ASM inhibitors were available in LincsCloud database. A set of genetic perturbations exhibited significant similarity to the ASM inhibitors (Figure 4E and Supplementary Table 8). Among these, knockdown of the genes involved in cellular endocytosis and vesicle trafficking (ATP6V0B, ATP6V0C, CHMP2A), genes involved in the Golgi to ER retrograde transport (COPA, COPB2, TMED10), and more interestingly RTK/AKT signalling proteins (ERBB3, KRAS, AKT3) exhibited similar signatures to ASM inhibitors (Figure 4E).

Disruption of intracellular vesicle trafficking, cellular endocytosis and the trans-Golgi network may retard maturation and localisation of certain proteins ( $\mathrm{Gu}$ et al, 2001). Leelaminemediated inhibition of cholesterol transport altered the localisation of several receptor tyrosine kinases and led to the accumulation of immature forms (Kuzu et al, 2014). Similarly, treatment with ASM inhibitors delocalised the IGF1R receptors to the perinuclear region and caused a dose-dependent accumulation of immature forms of HGFR, IGFIR and cathepsin B proteins while decreasing the levels of mature forms (Figure $4 \mathrm{~F}$ and $\mathrm{G}$ ). In agreement with RNA-Seq results, western blotting of ER stress markers, HERPUD1 and EROL $1 \alpha$ indicated the induction of ER stress by ASM inhibitors (Figure 4G). Collectively, these results suggested that inhibition of intracellular cholesterol transport by ASM inhibitors disrupted intracellular vesicle trafficking in the ER trans-Golgi network, impaired protein maturation and triggered the ER stress response(Grice et al, 2010).

Inhibition of intracellular cholesterol transport retarded RTK/ AKT/STAT3 signalling. Disrupted maturation and localisation of RTKs and inhibition of cellular endocytosis can suppress downstream signalling cascades regulated by these receptors (Sorkin and von Zastrow, 2009). Leelamine-mediated inhibition of intracellular cholesterol transport inhibited downstream PI3K/AKT and STAT3 signalling pathways (Kuzu et al, 2014). Similarly, ASM inhibitors suppressed pAKT, pPRAS40 and pSTAT3 levels (Figure 4G). 
Interestingly, pERK1/2 levels were upregulated possibly due to strong AKT inhibition, which has been observed following genetic or pharmacological inhibition of AKT signalling (Chen et al, 2012). Thus, inhibition of RTK/PI3K/AKT/STAT3 signalling could partially explain the enhanced sensitivity of cancer cells to ASM inhibitors, as many cancers are addicted to these oncogenic signalling cascades.

Cancer cells with high PI3K/AKT activity exhibited increased sensitivity to ASM inhibitors. PTEN deletion promotes prostate cancer aggressiveness via cholesteryl ester accumulation and consequent PI3K/AKT activation (Yue et al, 2014). Since, ASM inhibitors significantly downregulated AKT signalling, the potential association between loss of PTEN activity and increased sensitivity to cholesterol transport inhibition was investigated in a panel of melanoma and normal skin cell lines. Melanoma cells lacking functional PTEN showed enhanced sensitivity to ASM inhibitors, suggesting that ASM inhibitors might more effectively kill those cancer cells in which AKT signalling is activated (Figure $4 \mathrm{H}$ ).

Inhibition of intracellular cholesterol transport leads to caspaseindependent cell death that involves mitochondrial localisation of BAX. To characterise the mechanism of cell death mediated by ASM inhibitors, alterations in various cell death processes were examined. To identify alive $v s$ early and late apoptotic cells, UACC 903 cells were treated with ASM inhibitors for $24 \mathrm{~h}$ and stained with Annexin-V/Propidium iodide (PI). All of the tested agents led to a significant increase in the percentage of early apoptotic cells (Annexin-V +, PI - ) (Figure 5A). In the control cells, only $1 \%$ underwent apoptosis while that was dose-dependently increased to 4-8\% following ASM treatment. Furthermore, a dramatic increase from $0.5 \%$ to $10-37 \%$ was observed in late apoptotic/necrotic Annexin-V, PI-positive cells. Necrosis was not the cause of cell accumulation in this quadrant as neither of the two necrosis inhibitors, IM-54 and Necrostatin-5, protected UACC 903 cells from ASM inhibitor or leelamine-mediated cell death (Supplementary Figure 4A and B) (Galluzzi et al, 2012).

Next, loss of mitochondrial membrane potential (MMP) was assessed since it has a central role in many apoptotic processes and leelamine treatment decreased MMP (Ly et al, 2003; Kuzu et al, 2014). Following treatment with ASM inhibitors, UACC 903 cells were stained with Tetramethylrhodamine Ethyl Ester (TMRE), a cell-permeant fluorescent dye that accumulates in mitochondria in a membrane potential-dependent manner (Bernas and Dobrucki, 2002). As a positive control, FCCP which is an oxidative phosphorylation uncoupler was used, which effectively reduced the MMP of treated cells. Following $3 \mathrm{~h}$ of $10 \mathrm{umoll}^{-1}$ nortriptyline or perphenazine treatment, $15 \%$ of the cells lost MMP (Figure 5B). The decrease in MMP was dose and time-dependent as evidenced by a 19 and $28 \%$ decrease after $6 \mathrm{~h}$ of 10 or $15 \mathrm{um}$ perphenazine treatments, respectively.

To determine whether BAX, a proapoptotic member of the Bcl2 protein family that induces loss of MMP by translocating to the mitochondrial membrane, was involved in cell death, the sensitivity of wild-type and BAX-knockout HCT116 cells to ASM inhibitors was compared (Smaili et al, 2001). BAX-knockout cells were more resistant to increasing concentrations of perphenazine (Figure 5C; left). Moreover, all of the tested ASM inhibitors, more effectively killed wild-type HCT116 cells (Figure 5C; right). Mitochondrial localisation of BAX promotes assembly of the apoptosome and subsequent activation of caspases (GomezCrisostomo et al, 2013). Interestingly, the response of cells to NS-3694, an inhibitor of apoptosome formation, was variable, following co-treatment with various ASM inhibitors (Figure 5D). $50 \mu \mathrm{Mol} / 1$ NS-3694 partially protected cells from death mediated by perphenazine, fluphenazine or flupenthixol, but not desipramine, nortriptyline or leelamine treatments (Figure 5D).
Furthermore, cell death induced by ASM inhibitors was caspase-independent (Figure 5E). Pan-caspase inhibitor z-VADfmk, protected cells from apoptosis induced by positive control TRAIL treatment (Figure 5E; left). However, it was ineffective against cell death mediated by ASM inhibitors, suggesting induction of a caspase-independent cell death program (Figure 5E; right).

\section{DISCUSSION}

Cholesterol is an essential lipid for the proper functioning of the cell membrane and membrane-bound organelles (Ikonen, 2008). It has a key role modulating signal transduction from the membrane to cytoplasm and participates in intracellular vesicle trafficking (Ridsdale et al, 2006; Ikonen, 2008). Increased levels of cellular cholesterol and deregulation of its homoeostasis occur in various malignancies (Yue et al, 2014).

Recent studies have dissected the role of cellular cholesterol in cancer progression and suggested targeting it as a potential chemotherapeutic approach (Guo et al, 2011; Freed-Pastor et al, 2012; Sorrentino et al, 2014; Yue et al, 2014; Gabitova et al, 2015). Oncogenic signals initiated from RTK/MAPK, RTK/PI3K/AKT/ mTOR or mutant p53 were found to deregulate cholesterol synthesis in cancer cells (Guo et al, 2011; Freed-Pastor et al, 2012; Sorrentino et al, 2014; Gabitova et al, 2015). Mutant KRASmediated transformation increased the cellular demand for cholesterol (Gabitova et al, 2015). Activation of AKT pathway induced SREBP-mediated cholesterol synthesis and LDL receptormediated cholesterol import while shutting down ABCA1mediated cholesterol export (Porstmann et al, 2008; Guo et al, 2011). In prostate cancer, intracellular cholesterol levels enhanced by AKT signalling contributed to cancer aggressiveness and bone metastases (Thysell et al, 2010; Yue et al, 2014). In glioblastoma, LDL receptors were induced by over-activated AKT signalling and their pharmacological targeting effectively killed tumour cells (Guo et al, 2011). SREBP-mediated upregulation of cholesterol synthesis was induced by mutant $\mathrm{p} 53$, contributing to proliferation and selfrenewal of breast cancer cells (Freed-Pastor et al, 2012; Sorrentino et al, 2014). Collectively, these studies suggest that deregulated intracellular cholesterol homoeostasis plays an important role in cancer development.

Recently, inhibition of intracellular cholesterol transport has been shown to induce melanoma cell death (Kuzu et al, 2014). This study expands on these studies by showing that like Niemann-Pick disease, where loss of function mutations in ASM retard intracellular cholesterol transport, certain ASM inhibitors can block cholesterol egress from lysosomes to inhibit cancer cell survival. Upregulation of the genes in the cholesterol synthesis pathway following ASM inhibition suggested decreased cholesterol levels in the ER and potentially also in other membrane-bound organelles. The inhibition of intracellular cholesterol transport mediated by ASM inhibitors also disrupted cellular endocytosis and autophagic flux while causing ER stress and inhibiting AKT as well as STAT3 signalling cascades. Cancer cells with over-activated MAP kinase and PI3K/AKT pathways were threefold more sensitive to ASM inhibitors compared to normal skin cells. This observation could be associated with increased cholesterol demand by these cells due to upregulated MAPK/AKT/SREBP signalling. Moreover, activated AKT/mTOR signalling has been reported to increase proteasomal degradation of NPC1 protein which could also sensitise cancer cells to inhibition of cholesterol egress from lysosomes (Du et al, 2015).

Although lysosomotropic ASM inhibitors have been suggested to inhibit the function of the enzyme by disrupting the electrostatic attraction between intraluminal membranes and ASM, causing degradation of the enzyme by cathepsins, the exact mechanism still 




B

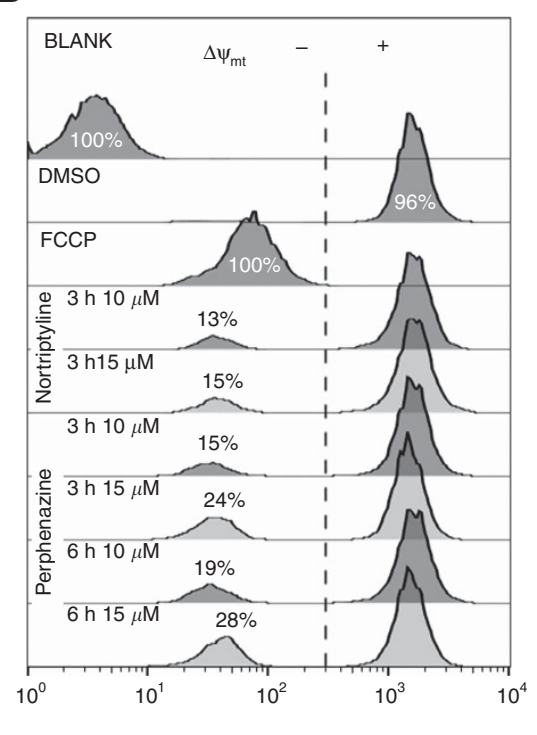

C
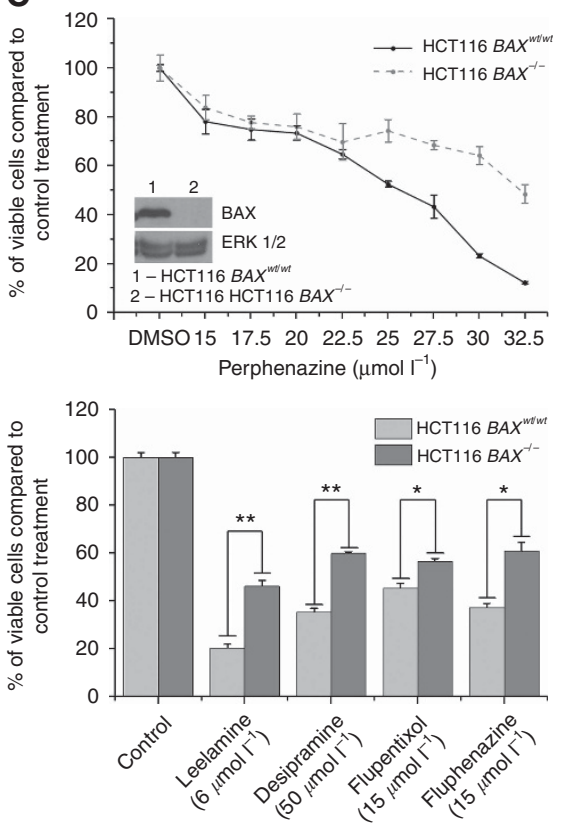
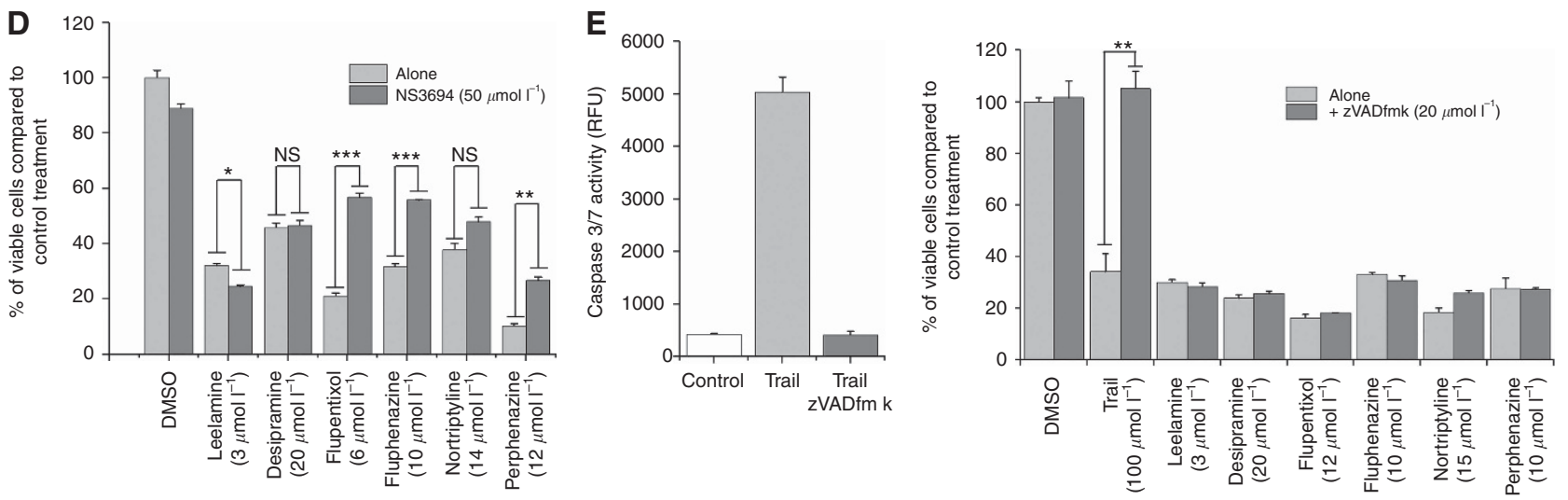

Figure 5. ASM inhibitor-mediated cell death involves disruption of MMP but not Caspase-3/7 activity. (A) flow cytometry analysis showing Annexin-V/PI staining of UACC 903 cells. Cells, in the lower and upper right quadrant show early and late apoptotic cells, respectively; (B) histogram showing MMP following treatment with ASM inhibitors or FCCP; (C) viability of wild-type or BAX-knockout HCT116 cells after $24 \mathrm{~h}$ of treatment with increasing concentrations of perphenazine (left) or other ASM inhibitors (right); (D) viability of UACC 903 cells treated with leelamine or ASM inhibitors in the absence or presence of apoptosome inhibitor NS3694; (E) caspase-dependent cell death measured by treatment of UACC 903 cells with or without pan-caspase inhibitor, z-VAD-fmk. TRAIL $\left(50 \mathrm{ng} \mathrm{ml}^{-1}\right)$ treatment served as a positive control for caspase-dependent cell death (left). ${ }^{*} P<0.05 ;{ }^{*} P<0.01 ;{ }^{* \star *} P<0.001$.

needs further study (Schulze et al, 2009; Petersen et al, 2013). Following lysosomotropic accumulation of ASM inhibitors, these agents could interfere with other lysosomal proteins such as NPC1 and NPC2. A recent study suggested U18666A to be a direct inhibitor of NPC1 (Lu et al, 2015).

CNS-active agents, such as tricyclic antidepressants and antipsychotics, also act as ASM inhibitor and have been suggested to prevent cancer in case-control and preclinical studies (Kornhuber et al, 2008; Lieb, 2008; Kornhuber et al, 2011). A case-control study that involved follow-up of a cohort of 6168 chronic schizophrenic patients over 27 years, identified decreased cancer risk for the respiratory system, prostate, bladder and uterine cervix cancers by using high-dose tricyclic antidepressants (Mortensen, 1989). Another case-control study showed an association between previous tricyclic antidepressant usage and cancer incidence (Walker et al, 2011). After stratifying for age, gender, smoking and alcohol usage, a statistically significant inverse association was found between previous tricyclic antidepressant usage and incidence of glioma as well as colorectal cancer, in a dose- and time-dependent manner. No linkage of the anti-ASM activity of these agents was reported, making this study the first to suggest a possible mechanism for these observations.

In preclinical studies, many antidepressants that also act as ASM inhibitors, have been shown to trigger cancer cell death and restore sensitivity of multidrug-resistant (MDR) cancer cell lines (Akiyama et al, 1986; Peer and Margalit, 2006). Perphenazine induced mitochondria-mediated cell death in human neuroblastoma cells and triggered apoptosis in both wild-type and MDR-B16 melanoma cells (Gil-Ad et al, 2006; Perez-Alvarez et al, 2011). Fluphenazine was also effective at killing MDR-B16 cells (Gil-Ad et al, 2006). Flupentixol enhanced the sensitivity of murine fibrosarcoma cells to anticancer drugs (Fan et al, 1994). Another antidepressant, desipramine-triggered apoptotic cell death of colon carcinoma cells (Arimochi and Morita, 2008). Thus, epidemiological and preclinical studies suggest that tricyclic antidepressants may also function as chemotherapeutic agents. Since many ASM inhibitors were shown to enhance sensitivity of drug-resistant cell lines to chemotherapeutic agents, it is possible that these agents 
could reverse the resistance to V600E-BRAF inhibitors in melanoma, which has been reported to involve activation of AKT and STAT3 signalling (Shao and Aplin, 2010; Liu et al, 2013).

Several compounds that act as an ASM inhibitor are currently being tested in clinical trials for therapeutic efficacy against leukaemia, myeloma, lung, prostate and colorectal cancers (Clinical Trial ID: NCT02096289, NCT00821301, NCT00417274, NCT01719861). The chemotherapeutic potential of quinacrine (mepacrine) on prostate cancer has been assessed in a phase- 2 trial (Clinical Trial Id: NCT00417274). The trial was conducted in patients who had not responded to previous chemotherapies. Although only one of the 31 patients showed a partial response to the treatment, $\sim 50 \%$ of the patients showed stabilisation or decrease in the rate of disease progression. More recently, the chemotherapeutic activity of desipramine was examined in a phase-IIa clinical study for small cell lung cancer (Clinical Trial Id: NCT01719861). The plan was to start treating patients at $75 \mathrm{mg} \mathrm{day}^{-1}$ and increase dosing to $450 \mathrm{mg} \mathrm{day}^{-1}$. However, only one patient was able to tolerate a dose above $150 \mathrm{mgday}^{-1}$ (personal communication). Failure to reach therapeutically effective dosing levels and lack of efficacy led to early study termination suggesting that alternative approaches for administering these drugs may be required for anticancer efficacy.

In this report, the significant anticancer activity of two ASM inhibitors, perphenazine and fluphenazine, was observed. Both agents led to decreased xenografted tumour development, but efficacy was limited by CNS-associated sedative side effects. The dose required for anticancer activity in mice were 4-10 times greater than the standard doses used in the clinic. These levels are impractical in humans and caused sedation of mice. In this study, nanoliposomal encapsulation of perphenazine was identified as a strategy to overcome the side effects of CNS-active agents that are ASM inhibitors. Nanoliposomal encapsulation would alter the pharmacokinetics and tissue distribution of the CNS-active agents by decreasing blood-brain-barrier permeability, protecting the agents from liver metabolism, and assisting in tumour penetration due to the EPR effect (Greish, 2007). Nanoliposomal encapsulation of perphenazine-reduced CNS-associated sedative effects of perphenazine, while enhancing the anticancer activity of the compound. Therefore certain ASM compounds with well-known toxicity profiles might be repurposed for use as anticancer agents by reformulation into nanoparticles.

\section{ACKNOWLEDGEMENTS}

We are thankful to Dr Arati Sharma for technical assistance with the animal studies. This work was supported by The Foreman Foundation for Melanoma Research, Geltrude Foundation, The Chocolate Tour Cancer Research Fund and NIH grants CA127892, CA-136667, and CA-138634.

\section{CONFLICT OF INTEREST}

The authors declare no conflict of interest.

\section{REFERENCES}

Akiyama S, Shiraishi N, Kuratomi Y, Nakagawa M, Kuwano M (1986) Circumvention of multiple-drug resistance in human cancer cells by thioridazine, trifluoperazine, and chlorpromazine. J Natl Cancer Inst 76(5): 839-844.

Anders S, Huber W (2010) Differential expression analysis for sequence count data. Genome Biol 11(10): R106.
Arimochi H, Morita K (2008) Desipramine induces apoptotic cell death through nonmitochondrial and mitochondrial pathways in different types of human colon carcinoma cells. Pharmacology 81(2): 164-172.

Bernas T, Dobrucki J (2002) Mitochondrial and nonmitochondrial reduction of MTT: interaction of MTT with TMRE, JC-1, and NAO mitochondrial fluorescent probes. Cytometry 47(4): 236-242.

Chen B, Tardell C, Higgins B, Packman K, Boylan JF, Niu H (2012) BRAFV600E negatively regulates the AKT pathway in melanoma cell lines. PLoS One 7(8): e42598.

Du X, Zhang Y, Jo SR, Liu X, Qi Y, Osborne B, Byrne FL, Smith GC, Turner N, Hoehn KL, Brown AJ, Yang H (2015) Akt activation increases cellular cholesterol by promoting the proteasomal degradation of Niemann-Pick C1. Biochem J 471(2): 243-253.

Fan D, Poste G, Seid C, Earnest LE, Bull T, Clyne RK, Fidler IJ (1994) Reversal of multidrug resistance in murine fibrosarcoma cells by thioxanthene flupentixol. Invest New Drugs 12(3): 185-195.

Freed-Pastor WA, Mizuno H, Zhao X, Langerod A, Moon SH, Rodriguez-Barrueco R, Barsotti A, Chicas A, Li W, Polotskaia A, Bissell MJ, Osborne TF, Tian B, Lowe SW, Silva JM, Borresen-Dale AL, Levine AJ, Bargonetti J, Prives C (2012) Mutant p53 disrupts mammary tissue architecture via the mevalonate pathway. Cell 148(1-2): 244-258.

Gabitova L, Restifo D, Gorin A, Manocha K, Handorf E, Yang DH, Cai KQ, Klein-Szanto AJ, Cunningham D, Kratz LE, Herman GE, Golemis EA, Astsaturov I (2015) Endogenous sterol metabolites regulate growth of EGFR/KRAS-dependent tumors via LXR. Cell Rep 12(11): 1927-1938.

Galluzzi L, Vitale I, Abrams JM, Alnemri ES, Baehrecke EH, Blagosklonny MV, Dawson TM, Dawson VL, El-Deiry WS, Fulda S, Gottlieb E, Green DR, Hengartner MO, Kepp O, Knight RA, Kumar S, Lipton SA, Lu X, Madeo F, Malorni W, Mehlen P, Nunez G, Peter ME, Piacentini M, Rubinsztein DC, Shi Y, Simon HU, Vandenabeele P, White E, Yuan J, Zhivotovsky B, Melino G, Kroemer G (2012) Molecular definitions of cell death subroutines: recommendations of the Nomenclature Committee on Cell Death 2012. Cell Death Differ 19(1): 107-120.

Garver WS, Krishnan K, Gallagos JR, Michikawa M, Francis GA, Heidenreich RA (2002) Niemann-Pick C1 protein regulates cholesterol transport to the trans-Golgi network and plasma membrane caveolae. J Lipid Res 43(4): 579-589.

Gil-Ad I, Shtaif B, Levkovitz Y, Nordenberg J, Taler M, Korov I, Weizman A (2006) Phenothiazines induce apoptosis in a B16 mouse melanoma cell line and attenuate in vivo melanoma tumour growth. Oncol Rep 15(1): $107-112$.

Gomez-Crisostomo NP, Lopez-Marure R, Zapata E, Zazueta C, Martinez-Abundis E (2013) Bax induces cytochrome $\mathrm{c}$ release by multiple mechanisms in mitochondria from MCF7 cells. J Bioenerg Biomembr 45(5): 441-448.

Gowda R, Madhunapantula SV, Kuzu OF, Sharma A, Robertson GP (2014) Targeting multiple key signaling pathways in melanoma using leelamine. Mol Cancer Ther 13(7): 1679-1689.

Greish K (2007) Enhanced permeability and retention of macromolecular drugs in solid tumors: a royal gate for targeted anticancer nanomedicines. J Drug Targeting 15(7-8): 457-464.

Grice DM, Vetter I, Faddy HM, Kenny PA, Roberts-Thomson SJ, Monteith GR (2010) Golgi calcium pump secretory pathway calcium ATPase 1 (SPCA1) is a key regulator of insulin-like growth factor receptor (IGF1R) processing in the basal-like breast cancer cell line MDA-MB-231. J Biol Chem 285(48): 37458-37466.

Gu F, Crump CM, Thomas G (2001) Trans-Golgi network sorting. Cell Mol Life Sci 58(8): 1067-1084.

Guo D, Reinitz F, Youssef M, Hong C, Nathanson D, Akhavan D, Kuga D, Amzajerdi AN, Soto H, Zhu S, Babic I, Tanaka K, Dang J, Iwanami A, Gini B, Dejesus J, Lisiero DD, Huang TT, Prins RM, Wen PY, Robins HI, Prados MD, Deangelis LM, Mellinghoff IK, Mehta MP, James CD, Chakravarti A, Cloughesy TF, Tontonoz P, Mischel PS (2011) An LXR agonist promotes glioblastoma cell death through inhibition of an EGFR/ AKT/SREBP-1/LDLR-dependent pathway. Cancer Discov 1(5): 442-456.

Ikonen E (2008) Cellular cholesterol trafficking and compartmentalization. Nat Rev Mol Cell Biol 9(2): 125-138.

Kornhuber J, Muehlbacher M, Trapp S, Pechmann S, Friedl A, Reichel M, Muhle C, Terfloth L, Groemer TW, Spitzer GM, Liedl KR, Gulbins E, Tripal P (2011) Identification of novel functional inhibitors of acid sphingomyelinase. PloS One 6(8): e23852. 
Kornhuber J, Tripal P, Reichel M, Terfloth L, Bleich S, Wiltfang J, Gulbins E (2008) Identification of new functional inhibitors of acid sphingomyelinase using a structure-property-activity relation model. J Med Chem 51(2): 219-237.

Kuzu OF, Gowda R, Sharma A, Robertson GP (2014) Leelamine mediates cancer cell death through inhibition of intracellular cholesterol transport. Mol Cancer Ther 13(7): 1690-1703.

Lamb J, Crawford ED, Peck D, Modell JW, Blat IC, Wrobel MJ, Lerner J, Brunet JP, Subramanian A, Ross KN, Reich M, Hieronymus H, Wei G, Armstrong SA, Haggarty SJ, Clemons PA, Wei R, Carr SA, Lander ES, Golub TR (2006) The Connectivity Map: using gene-expression signatures to connect small molecules, genes, and disease. Science 313(5795): 1929-1935.

Lieb J (2008) The multifaceted value of antidepressants in cancer therapeutics. Eur J Cancer 44(2): 172-174.

Liu AP, Aguet F, Danuser G, Schmid SL (2010) Local clustering of transferrin receptors promotes clathrin-coated pit initiation. J Cell Biol 191(7): 1381-1393.

Liu F, Cao J, Wu J, Sullivan K, Shen J, Ryu B, Xu Z, Wei W, Cui R (2013) Stat3-targeted therapies overcome the acquired resistance to vemurafenib in melanomas. J Invest Dermatol 133(8): 2041-2049.

Lloyd-Evans E, Morgan AJ, He X, Smith DA, Elliot-Smith E, Sillence DJ, Churchill GC, Schuchman EH, Galione A, Platt FM (2008) Niemann-Pick disease type $\mathrm{C} 1$ is a sphingosine storage disease that causes deregulation of lysosomal calcium. Nat Med 14(11): 1247-1255.

Lu F, Liang Q, Abi-Mosleh L, Das A, De Brabander JK, Goldstein JL, Brown MS (2015) Identification of NPC1 as the target of U18666A, an inhibitor of lysosomal cholesterol export and Ebola infection. eLife 4: pii: e12177.

Ly JD, Grubb DR, Lawen A (2003) The mitochondrial membrane potential (deltapsi(m)) in apoptosis; an update. Apoptosis 8(2): 115-128.

Marceau F, Bawolak MT, Lodge R, Bouthillier J, Gagne-Henley A, Gaudreault RC, Morissette G (2012) Cation trapping by cellular acidic compartments: beyond the concept of lysosomotropic drugs. Toxicol Appl Pharmacol 259(1): 1-12.

Montero J, Morales A, Llacuna L, Lluis JM, Terrones O, Basanez G, Antonsson B, Prieto J, Garcia-Ruiz C, Colell A, Fernandez-Checa JC (2008) Mitochondrial cholesterol contributes to chemotherapy resistance in hepatocellular carcinoma. Cancer Res 68(13): 5246-5256.

Mortensen PB (1989) The incidence of cancer in schizophrenic patients. J Epidemiol Community Health 43(1): 43-47.

N’Diaye EN, Kajihara KK, Hsieh I, Morisaki H, Debnath J, Brown EJ (2009) PLIC proteins or ubiquilins regulate autophagy-dependent cell survival during nutrient starvation. EMBO Rep 10(2): 173-179.

Nadanaciva S, Lu S, Gebhard DF, Jessen BA, Pennie WD, Will Y (2011) A high content screening assay for identifying lysosomotropic compounds. Toxicol In Vitro 25(3): 715-723.

Nielsen SF, Nordestgaard BG, Bojesen SE (2013) Statin use and reduced cancer-related mortality. N Engl J Med 368(6): 576-577.

Ohlow MJ, Moosmann B (2011) Phenothiazine: the seven lives of pharmacology's first lead structure. Drug Discov Today 16(3-4): 119-131.

Peake KB, Vance JE (2010) Defective cholesterol trafficking in Niemann-Pick C-deficient cells. FEBS Lett 584(13): 2731-2739.

Peer D, Margalit R (2006) Fluoxetine and reversal of multidrug resistance. Cancer Lett 237(2): 180-187.

Perez-Alvarez S, Iglesias-Guimarais V, Solesio ME, Melero-Fernandez de Mera RM, Yuste VJ, Galindo MF, Jordan J (2011) Methadone induces CAD degradation and AIF-mediated necrotic-like cell death in neuroblastoma cells. Pharmacol Res 63(4): 352-360.

Petersen NH, Olsen OD, Groth-Pedersen L, Ellegaard AM, Bilgin M, Redmer S, Ostenfeld MS, Ulanet D, Dovmark TH, Lonborg A, Vindelov SD, Hanahan D, Arenz C, Ejsing CS, Kirkegaard T, Rohde M, Nylandsted J, Jaattela M (2013) Transformation-associated changes in sphingolipid metabolism sensitize cells to lysosomal cell death induced by inhibitors of acid sphingomyelinase. Cancer Cell 24(3): 379-393.

Platz EA, Clinton SK, Giovannucci E (2008) Association between plasma cholesterol and prostate cancer in the PSA era. Int J Cancer 123(7): 1693-1698.

Polo S, Pece S, Di Fiore PP (2004) Endocytosis and cancer. Curr Opin Cell Biol 16(2): 156-161.

Porstmann T, Santos CR, Griffiths B, Cully M, Wu M, Leevers S, Griffiths JR, Chung YL, Schulze A (2008) SREBP activity is regulated by mTORC1 and contributes to Akt-dependent cell growth. Cell Metab 8(3): 224-236.

Ridsdale A, Denis M, Gougeon PY, Ngsee JK, Presley JF, Zha X (2006) Cholesterol is required for efficient endoplasmic reticulum-to-Golgi transport of secretory membrane proteins. Mol Biol Cell 17(4): 1593-1605.

Schulze H, Kolter T, Sandhoff K (2009) Principles of lysosomal membrane degradation: Cellular topology and biochemistry of lysosomal lipid degradation. Biochim Biophys Acta 1793(4): 674-683.

Shao Y, Aplin AE (2010) Akt3-mediated resistance to apoptosis in B-RAFtargeted melanoma cells. Cancer Res 70(16): 6670-6681.

Smaili SS, Hsu YT, Sanders KM, Russell JT, Youle RJ (2001) Bax translocation to mitochondria subsequent to a rapid loss of mitochondrial membrane potential. Cell Death Differ 8(9): 909-920.

Smith B, Land H (2012) Anticancer activity of the cholesterol exporter ABCA1 gene. Cell Rep 2(3): 580-590.

Sorkin A, von Zastrow M (2009) Endocytosis and signalling: intertwining molecular networks. Nat Rev Mol Cell Biol 10(9): 609-622.

Sorrentino G, Ruggeri N, Specchia V, Cordenonsi M, Mano M, Dupont S, Manfrin A, Ingallina E, Sommaggio R, Piazza S, Rosato A, Piccolo S, Del Sal G (2014) Metabolic control of YAP and TAZ by the mevalonate pathway. Nat Cell Biol 16(4): 357-366.

Thysell E, Surowiec I, Hornberg E, Crnalic S, Widmark A, Johansson AI, Stattin P, Bergh A, Moritz T, Antti H, Wikstrom P (2010) Metabolomic characterization of human prostate cancer bone metastases reveals increased levels of cholesterol. PloS One 5(12): e14175.

Urano Y, Watanabe H, Murphy SR, Shibuya Y, Geng Y, Peden AA, Chang CC, Chang TY (2008) Transport of LDL-derived cholesterol from the NPC1 compartment to the ER involves the trans-Golgi network and the SNARE protein complex. Proc Natl Acad Sci USA 105(43): 16513-16518.

Vanier MT (2013) Niemann-Pick diseases. Handb Clin Neurol 113: $1717-1721$.

Walker AJ, Card T, Bates TE, Muir K (2011) Tricyclic antidepressants and the incidence of certain cancers: a study using the GPRD. Br J Cancer 104(1): 193-197.

Yue S, Li J, Lee SY, Lee HJ, Shao T, Song B, Cheng L, Masterson TA, Liu X, Ratliff TL, Cheng JX (2014) Cholesteryl ester accumulation induced by PTEN loss and PI3K/AKT activation underlies human prostate cancer aggressiveness. Cell Metab 19(3): 393-406.

Zhao B, Li Y, Buono C, Waldo SW, Jones NL, Mori M, Kruth HS (2006) Constitutive receptor-independent low density lipoprotein uptake and cholesterol accumulation by macrophages differentiated from human monocytes with macrophage-colony-stimulating factor (M-CSF). J Biol Chem 281(23): 15757-15762.

Zoncu R, Bar-Peled L, Efeyan A, Wang S, Sancak Y, Sabatini DM (2011) mTORC1 senses lysosomal amino acids through an inside-out mechanism that requires the vacuolar H( + )-ATPase. Science 334(6056): 678-683.

This work is published under the standard license to publish agreement. After 12 months the work will become freely available and the license terms will switch to a Creative Commons AttributionNonCommercial-Share Alike 4.0 Unported License.

Supplementary Information accompanies this paper on British Journal of Cancer website (http://www.nature.com/bjc) 